\title{
Measurement of nitric oxide in human nasal airway
}

\author{
M. Imada*, J. Iwamoto**, S. Nonaka*, Y. Kobayashi*, T. Unno*
}

Measurement of nitric oxide in human nasal airway. M. Imada, J. Iwamoto, S. Nonaka, Y. Kobayashi, T. Unno. (CERS Journals Ltd 1996.

ABSTRACT: The nasal output of nitric oxide (NO) is known to be high, but there have been varying reports of the exact level. We attempted to establish a quantitative measurement of nasal NO, and looked for a possible relationship with nasal resistance, at rest and during exercise.

Nasal airway ventilation was performed by using an air pump at a constant flow rate, whilst the soft palate was elevated voluntarily. In a preliminary study, the flow rate for sampling was changed and concentrations of NO were measured. After determination of flow rate, rhinomanometry for nasal resistance and measurement of nasal NO by chemiluminescence were carried out before and after moderate exercise.

The concentration of NO ([NO]) exhibited a hyperbolic relationship with flow rate of ventilation $\left(V^{\prime} \mathrm{E}\right)$, indicating [NO] $\times V^{\prime} \mathrm{E}=$ net nitric oxide output $\left(V^{\prime} \mathrm{NO}\right)=$ constant. Hence, nasal NO was expressed quantitatively as $V^{\prime}$ NO $\left(\mathrm{nL} \cdot \mathrm{min}^{-1}\right)$. For $1 \mathrm{~L} \cdot \mathrm{min}^{-1}$ of ventilation, [NO] varied between 2 and 500 parts per billion (ppb) $($ mean $=323 \mathrm{ppb})$. The average nasal $V^{\prime}$ No in 12 healthy male subjects was $323 \pm 91$ $\mathrm{nL} \cdot \mathrm{min}^{-1}($ mean $\pm \mathrm{SD})$. After exercise on a treadmill $\left(10^{\circ}, 5 \mathrm{~km} \cdot \mathrm{h}^{-1}\right)$ for $4 \mathrm{~min}$, nasal $V^{\prime}$ 'NO decreased to $229 \pm 63 \mathrm{~nL} \cdot \mathrm{min}^{-1}$. At rest, expiratory and inspiratory nasal resistance was $0.27 \pm 0.04$ and $0.27 \pm 0.06 \mathrm{~Pa} \cdot \mathrm{s}^{\cdot} \cdot \mathrm{cm}^{-3}$, respectively. After exercise, expiratory and inspiratory nasal resistance decreased to $0.17 \pm 0.04$ and $0.16 \pm 0.04 \mathrm{~Pa} \cdot \mathrm{s} \cdot \mathrm{cm}^{-3}$, respectively.

These data indicate that nasal NO can be measured quantitatively as $V^{\prime}$ No and might be involved in the control of nasal resistance.

Eur Respir J., 1996, 9, 556-559.
Depts of *Otorhinolaryngology and **Physiology, Asahikawa Medical College, Asahikawa, Japan.

Correspondence: J. Iwamoto

Dept of Physiology

Asahikawa Medical College

Asahikawa

Hokkaido 078

Japan

Keywords: Exercise

nasal resistance

nitric oxide $(\mathrm{NO})$

Received: June 281995

Accepted after revision January 81996

This work was supported by research grants 07670077, 07557185 and 07771421 from the Japanese Ministry of Education, Science, Sports and Culture
Nitric oxide (NO) has been detected by chemiluminescence in the lumens of nasal airway [1, 2], lung [3, 4], stomach [5], and colon [6]. However, quantitative measurement has been performed in only a few studies on exhaled NO [7, 8] and nasal NO [9]. In the nasal airway, NO was first detected by Alving et al. [2] (1993). These authors found that most exhaled NO comes from the nose because of some 10 fold higher concentration of nasal NO than of exhaled NO. In general, a concentration of a gas rising from the wall of the lumen should vary with the amount of ventilation. Accordingly, the concentration of exhaled NO has been reported to correlate hyperbolically with a ventilatory volume, whereas the net output of $\mathrm{NO}\left(V^{\prime} \mathrm{NO}\right)$ remained constant [8]. We applied the same method in attempting to establish a quantitative measurement of the nasal airway $\mathrm{NO}$, and investigated the relationship between nasal airway NO and the nasal resistance before and after exercise.

\section{Materials and methods}

\section{Subjects and protocol}

Twelve male subjects (aged 27-35 years), with no allergies or abnormal rhinoscopic findings, volunteered for this study. The protocol of the study was reviewed and approved by the Asahikawa Medical College Institutional Review Board for Research. Subjects rested in a sitting position for at least $15 \mathrm{~min}$, during the last $5 \mathrm{~min}$ of which rhinomanometry and the measurement of nasal airway NO were performed. Subjects then walked on a $10^{\circ}$ graded treadmill at $5 \mathrm{~km} \cdot \mathrm{h}^{-1}$ for $4 \mathrm{~min}$. Immediately after exercise, subjects sat down and the measurements were repeated.

\section{Rhinomanometry}

The anterior method of rhinomanometry [10] was applied to obtain nasal resistance of each side of the nasal airway. From the flow-pressure curve obtained by rhinomanometry (model SR-11, Rion, Japan), nasal resistance at $100 \mathrm{~Pa}$ was taken as the nasal resistance value $\left(\mathrm{Pa} \cdot \mathrm{s} \cdot \mathrm{cm}^{-3}\right)$ for each subject. The total nasal resistance for both nasal airways was obtained by calculating the sum of the reciprocals of parallel resistance for each nasal airway.

\section{Measurement of nasal airway NO}

The quantitative measurement of NO in the human exhaled gas has already been established [8]:

$$
V^{\prime} \mathrm{NO}=[\mathrm{NO}] \cdot V^{\prime} \mathrm{E}
$$


where [NO] is the concentration of $\mathrm{NO}$, and $V^{\prime} \mathrm{E}$ is the ventilatory flow rate. When [NO] is expressed in parts per billion (ppb) and $V^{\prime} \mathrm{E}$ is in $\mathrm{L} \cdot \mathrm{min}^{-1}$, the products of $1 \mathrm{ppb} \times 1 \mathrm{~L} \cdot \mathrm{min}^{-1}$ gives $10^{-9} \times 1 \mathrm{~L} \cdot \mathrm{min}^{-1}$, i.e. $1 \mathrm{~nL} \cdot \mathrm{min}^{-1}$. Usually, the ppb unit is already standardized at $20^{\circ} \mathrm{C}$, so it would be easier to correct $V^{\prime} \mathrm{E}$ for the same temperature, or possibly to express $V^{\prime}$ NO in body temperature, atmospheric pressure and water saturation (BTPS), particularly for exhaled NO. However, the temperature of nasal airway NO is much closer to ambient temperature, therefore we used an ambient temperature atmospheric pressure and water saturation (ATPS) unit. Ventilation of the nasal airway was performed by using a constantflow air-pump at $1 \mathrm{~L} \cdot \mathrm{min}^{-1}$ in room air. The concentration of NO in room air was continuously monitored whilst sampling the local ventilated gas, and it was always less than $4 \mathrm{ppb}$.

The nasal airway was isolated by voluntary soft palate elevation from the lower airway and ventilated by a diaphragm pump. The setting of the flow rate at $1 \mathrm{~L} \cdot \mathrm{min}^{-1}$ was determined according to two factors: a volume of sample gas sufficient to avoid error in the measurements of NO by the environmental NO analyser, which demands a larger quantity of sample to obtain a stable plateau; and the drying effect of airflow on the nasal mucosa. After tight attachment of a fitting disc with Tygon tube (inside diameter (I.D.) 5/32, outside diameter (O.D.) 7/32) onto the nasal orifice using double-sided adhesive tape, an air-pump connected to the tube was driven for $15 \mathrm{~s}$ to collect a $250 \mathrm{~mL}$ sample of gas in a $3.5 \mathrm{~L}$ meteorological balloon (Collins, MA, USA). There was a threeway stopcock between the balloon and the pump to prevent accidental collection of ambient air. The dead space of the total circuit from nasal orifice to the collection balloon was less than $15 \mathrm{~mL}$.

Before each sampling, the meteorological balloon was washed out and aspirated. During sampling, subjects were asked to pressurize the oral cavity slightly by breathholding. It was confirmed by oral fibrescopy that this manoeuvre enabled raising of the soft palate to create an isolated nasal airway space and prevented an inflow of exhaled air into the nasal cavity. The validity of this manoeuvre was also confirmed by the measurement of carbon dioxide in a sampled gas for each measurement. Since the sampling technique may affect the collection of NO-containing air, the timing of the following protocol was performed as accurately as possible.

After attachment of the collection tubing, the subject was still breathing normally via the nose, while the pump started to ventilate the nasal airway. After 5-10 s, when the subject was given an indication of breathholding, he first exhaled and inhaled a tidal volume and then held a breath with his cheeks ballooning. This procedure enabled wash-out of both nasal airways and the collection circuit by a last inspiratory air because a stopcock lever was positioned to be open to the ambient air. When the breathholding began, the stopcock was opened to the circuit and gas sampling was started. Two to three measurements were made on each occasion, and it was found that the values were highly reproducible. The measurement of $[\mathrm{NO}$ ] by chemiluminescence (model CLD700

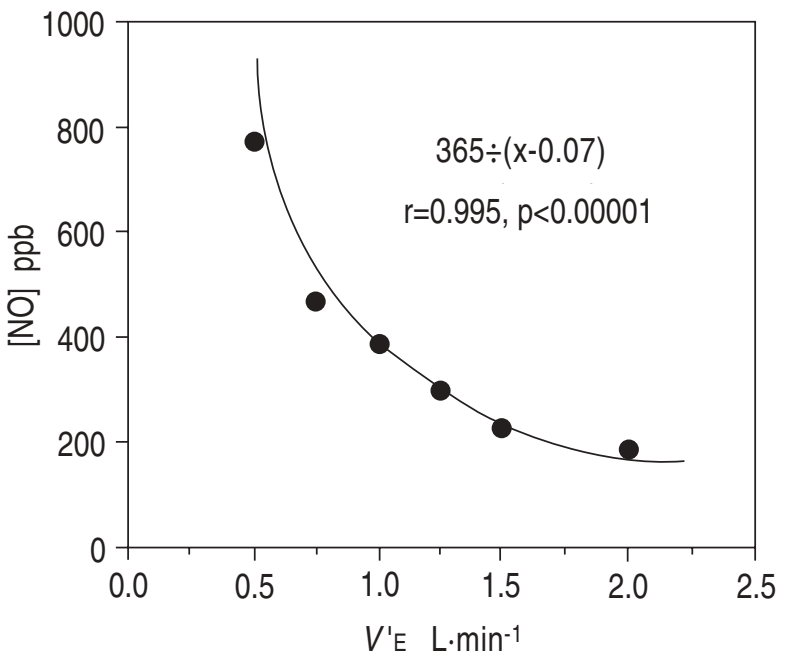

Fig. 1. - Hyperbolic relationship between nitric oxide concentration [NO] detected by chemiluminescence analyser and sampling flow rate. Sampling airflow is preadjusted by using a mass flowmeter. Data are obtained from one subject. Nasal nitric oxide output ( $V^{\prime}$ NO) is a product of $[\mathrm{NO}] \times$ flow rate $\left(V^{\prime} \mathrm{E}\right)$, and has a constant value of $365 \mathrm{~nL} \cdot \mathrm{min}^{-1}$ at various given flow rates. $\mathrm{p}<0.00001$ by Student's t-test.

AL, EcoPhysics, Switzerland) was carried out after dilution of the sample gas with $2 \mathrm{~L}$ of $\mathrm{NO}$-free $\mathrm{N}_{2}$ gas $(<1$ $\mathrm{ppb}$ ) to obtain a stable plateau curve of [NO]. The original $[\mathrm{NO}]$ value was calculated according to the dilution ratio, which is equal to $V^{\prime}$ NO value since the nose was ventilated at $1 \mathrm{~L} \cdot \mathrm{min}^{-1}$.

\section{Statistics}

Comparisons between control and postexercise values of nasal resistance and nasal airway NO were performed by analysis of variance (ANOVA) for repeated measures, followed by Scheffe's test. A p value of less than 0.05 was taken as statistically significant.

\section{Results}

[NO] had a hyperbolic relationship with $V^{\prime}$ E (fig. 1). Therefore, the product of $[\mathrm{NO}] \times V^{\prime} \mathrm{E}$, i.e. $V^{\prime} \mathrm{NO}$, was constant. At steady-state, nasal $V^{\prime} \mathrm{NO}$ (nasal NO output) was stable and reproducible at any rate of ventilation between 0.5 and $2.0 \mathrm{~L} \cdot \mathrm{min}^{-1}$.

The average nasal $V^{\prime}$ NO in 12 subjects was $323 \pm 91$ $\mathrm{nL} \cdot \mathrm{min}^{-1}$ (table 1). After exercise, nasal $V^{\prime}$ NO decreased to $229 \pm 63 \mathrm{~nL} \cdot \mathrm{min}^{-1}(\mathrm{p}<0.001)$ (table 1$)$. Nasal resistance at rest in expiratory and inspiratory periods was

Table 1. - Nasal resistance and nasal nitric oxide output ( $V^{\prime}$ No)

\begin{tabular}{|c|c|c|c|}
\hline & \multicolumn{2}{|c|}{ Nasal resistance $\mathrm{Pa} \cdot \mathrm{s} \cdot \mathrm{min}^{-3}$} & \multirow{2}{*}{$\begin{array}{c}\text { Nasal } V^{\prime} \mathrm{NO} \\
\mathrm{nL} \cdot \mathrm{min}^{-1}\end{array}$} \\
\hline & Inspiratory & Expiratory & \\
\hline & $0.27 \pm 0.06$ & $0.27 \pm 0.04$ & $323 \pm 91$ \\
\hline Post-exercise & $0.16 \pm 0.04 *$ & $0.17 \pm 0.04 *$ & $229 \pm 63 *$ \\
\hline
\end{tabular}

Values are presented as mean \pm SD. $*: \mathrm{p}<0.001$ vs corresponding resting values by analysis of variance (ANOVA) for repeated measures followed by Scheffe's test. 

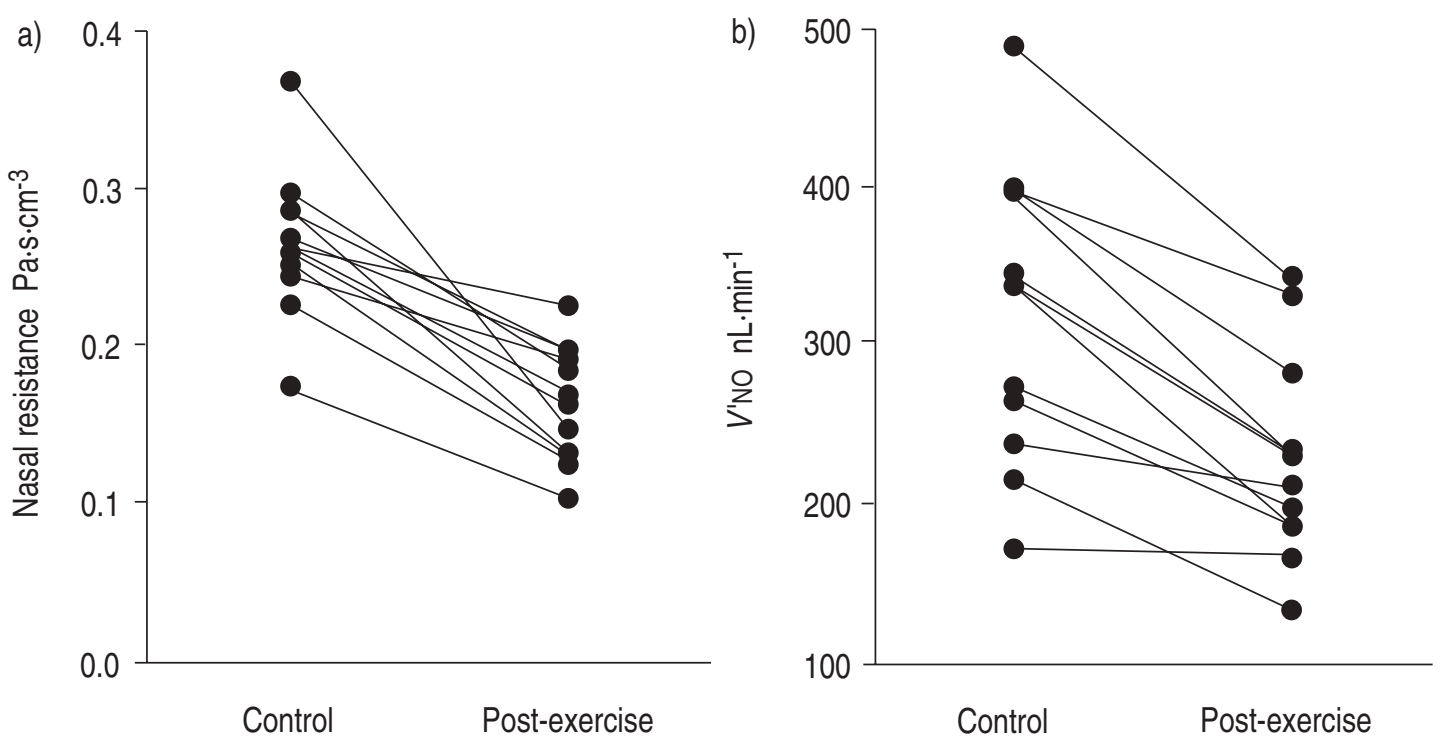

Fig. 2. - a) Changes of nasal resistance after exercise. Nasal resistance was measured by anterior rhinomanometry. b) Changes of nasal nitric oxide output $\left(V^{\prime}\right.$ No) after exercise. $V^{\prime}$ No was calculated using the following equation [NO] $\times$ flow rate $\left(V^{\prime} \mathrm{E}\right)$ (see fig. 1$)$. See table 1 for meaned data and statistical analysis.

$0.27 \pm 0.04$ and $0.27 \pm 0.06 \mathrm{~Pa} \cdot \mathrm{s} \cdot \mathrm{cm}^{-3}$, respectively (table 1). After exercise, the inspiratory nasal resistance for all individuals decreased (fig. 2), and the average of nasal resistance decreased (table 1). These effects on NO and nasal resistance could last at least 10-15 minutes after end of exercise.

\section{Discussion}

\section{Basal value of nasal airway NO}

Recently, nasal airway NO was measured as 468 $\mathrm{nL} \cdot \mathrm{min}^{-1}$ with the method of voluntary closure of the soft palate [9], which was almost the same method as that used in the present study. There may be many physiological and pathological factors that can modulate the basal value of nasal airway NO. The ventilation of the nose in the study by KIMBERLY et al. [9] was performed by infusing air from one nostril to the other with voluntary closure of the soft palate at the higher rate of 4-6 $\mathrm{L} \cdot \mathrm{min}^{-1}$. The wash-out effect with this method might be greater than that of our method, in which the nose was ventilated at $1 \mathrm{~L} \cdot \mathrm{min}^{-1}$ by a constant withdrawal of air from one nostril. However, withdrawal ventilation may be beneficial for maintaining soft palate closure. Utilization of a $1 \mathrm{~L} \cdot \mathrm{min}^{-1}$ flow rate also makes the calculation of nasal $V^{\prime}$ NO easier (see Method).

\section{Concentration of nasal NO and net NO output}

The concentration of NO measured by various flow rates exhibited a hyperbolic relationship with the flow rate of ventilation $\left(V^{\prime} \mathrm{E}\right)$. This suggests that nasal $\mathrm{NO}$ is excreted into the nasal cavity at a constant rate at rest. A similar phenomenon was observed for exhaled NO from the lungs [8]. Therefore, both nasal $V^{\prime}$ NO and exhaled $V$ 'No from lungs can be quantitatively measured as a stable value.

\section{Exercise and nasal airway NO}

It has been recognized that exercise can reduce nasal resistance [11-13]. This effect is mainly attributed to vasoconstriction of capacitance vessels in the nasal mucosa by sympathetic activity, since the decrease of nasal resistance by exercise was partially blocked by topical phentolamine in the nasal cavity and totally abolished by stellate ganglion block [12]. However, it has been demonstrated that the blood flow of the nasal mucosa does not change greatly during exercise $[14,15]$. In spite of many attempts to clarify the mechanism of nasal resistance reduction by exercise, it still remains uncertain.

A decrease in nasal airway NO caused by exercise is reported for the first time in the present study. Since NO is a vasodilatory substance, it is possible to speculate that the reduction of the mucosal blood flow by lowering NO during exercise may lead to a shrinkage of the mucosal layer and a decrease of nasal resistance. Recently, Busch et al. [16] reported that the NO production in the nose remained nearly constant after exercise. This discrepancy is probably due to a difference in the gas collecting technique from the nasal cavity. Whilst we collected the gas from the nasal cavity isolated from the lower airway by voluntary closure of soft palate, Busch et al. [16] asked subjects to breathe through the mouth. It is apparent that soft palate closure is critical for the measurement of nasal NO to avoid contamination by exhaled air from the lower airway [9]. In addition, it has been reported that exhaled NO from the lower airways tends to increase during exercise [8]. Thus, a rise of lower airway NO and a fall of nasal NO might have balanced each other out in the study by Busch et al. [16]. 
Anatomical analogy between the penile corpus cavernosum and the nasal tissue suggests that NO may be involved in the vasomotor regulation of both of these vessels. Indeed, NO synthase is abundant in the parasympathetic neural tissues in the pterygopalatine ganglion and the nasal mucosa $[17,18]$. It is noteworthy that NO synthase is also abundant in the pelvic plexus, corpus cavernosum and membranous urethra [19]. Such histological evidence strongly suggests that the nasal airway NO originated in parasympathetic neurons (probably from the pterygopalatine ganglion) in the nasal mucosa. If so, the physiological regulation of nasal resistance by the parasympathetic nervous system must be reconsidered. However, the real origin of nasal airway NO is still unclear and requires further investigation.

Acknowledgements: The authors thank T. Hanazawa for helpful discussion. They also thank NITI-ON Medical Supply Co. Ltd for kindly lending the NO-analyser.

\section{References}

1. Lundberg JON, Weitzberg E, Nordvall SL, Kuylenstierna $\mathrm{R}$, Lundberg JM, Alving K. Primarily nasal origin of exhaled nitric oxide and absence in Kartagener's syndrome. Eur Respir J 1994; 7: 1501-1504.

2. Alving K, Weitzberg E, Lundberg JM. Increased amount of nitric oxide in exhaled air of asthmatics. Eur Respir $J$ 1993; 6: 1368-1370.

3. Gustafsson LE, Leone AM, Persson MG, Wiklund NP, Moncada S. Endogenous nitric oxide is present in the exhaled air of rabbits, guinea-pigs and humans. Biochem Biophys Res Commun 1991; 181: 852-857.

4. Persson MG, Wilkund NP, Gustafsson LE. Endogenous nitric oxide in single exhalations and the change during exercise. Am Rev Respir Dis 1993; 148: 1210-1214.

5. Lundberg JO, Weitzberg E, Lundberg JM, Alving K.
Intragastric nitric oxide production in humans: measurements in expelled air. Gut 1994; 35(11): 1543-1546.

6. Lundberg JON, Hellstrom PM, Lundberg JM, Alving K. Greatly increased luminal nitric oxide in ulcerative colitis. Lancet 1994; 344: 1673-1674.

7. Borland C, Cox Y, Higenbottam T. Measurement of exhaled nitric oxide in man. Thorax 1993; 48: 1160-1162.

8. Iwamoto J, Pendergast DR, Suzuki H, Krasney JA. Effect of graded exercise on nitric oxide in expired air in humans. Respir Physiol 1994; 97: 333-345.

9. Kimberly B, Nejadnik B, Giraud GD, Holden WE. Nasal contribution to exhaled nitric oxide in humans. Am J Respir Crit Care Med 1995; 151(4): A128.

10. Unno T, Naitoh Y, Sakamoto N. Nasal resistance measured by anterior rhinomanometry. Rhinology 1986; 24 : 49-55.

11. Olson LG, Strohl KP. The response of the nasal airway to exercise. Am Rev Respir Dis 1987; 135: 356-359.

12. Richerson HB, Seebohm PM. Nasal airway response to exercise. J Allergy 1968; 41: 269-284.

13. Forsyth RD, Cole P, Shephard RJ. Exercise and nasal patency. J Appl Physiol 1983; 55(3): 860-865.

14. Ohki M, Hasegawa M, Kurita N, Watanabe I. Effects of exercise on nasal resistance and nasal blood flow. Acta Otolaryngol (Stockh) 1987; 104: 328-333.

15. Paulsson B, Bende M, Ohlin P. Nasal mucosal blood flow at rest and during exercise. Acta Otolaryngol 1985; 99: 140-143.

16. Busch T, Knorr M, Kuhlen R, Gerlach H, Rossaint R, Falke KJ. Exhaled nitric oxide at rest and during exercise. Am J Respir Crit Care Med 1995; 151: A480.

17. Hanazawa T, Motosugi H, Konno A, Kaneko T, Tanaka $\mathrm{K}$, Chiba T. Distribution of NADPH-diaphorase positive nerve fibers in the rat nasal mucosa. Neurosci Lett 1993; 159: 71-74.

18. Hanazawa T, Konno A, Kaneko T, et al. Nitric oxide synthase-immunoreactive nerve fibers in the nasal mucosa of the rat. Brain Res 1994; 657: 7-13.

19. Burnett AL, Lowenstein CJ, Bredt DS, Chang TSK, Snyder SH. Nitric oxide: a physiological mediator of penile erection. Science 1992; 257: 401-403. 